\title{
THANATOS I PAIDEIA*
}

\author{
Joan Carles MÈLICH
}

$\mathrm{Ni}$ amb aquest cant de tan perfecta escola, ni amb mots apresos al més savi lèxic, ni amb rares pauses o subtils silencis, no esgotaràs tots els noms de la mort.

\section{Salvador Espriu}

El present discurs s'inscriu sota el nom acadèmic de la filosofia de l'educació. El terme inclou dos aspectes que - aparentment- poden semblar contradictoris: filosofia i educació. La primera sembla que es mou en el camp teòric, la segona en el pràctic.

El filòsof alemany G. W. F. Hegel escrivia en la Filosofia del dret: "L'òliba de Minerva aixeca el vol quan ja ha arribat el crepuscle»' ${ }^{\prime}$ La filosofia, per tant, hauria de descriure la realitat, descobrir. la, desvelar-la.

I l'educació? La paideia seria la pràctica filosòfica. Com? Si no volem crear individus contraris a la seva pròpia realitat, a la seva autèntica constitució, l'educació hauria de formar éssers conformes a la seva estructura ontològico-existencial que la filosofia (antropologia filosòfica) ha descrit. La pedagogia - com a teoria prescriptiva de l'educació que és- tindria la tasca de mostrar els mit* jans per assolir-ho' ${ }^{2}$.

Entenem, doncs, per filosofia de l'educació (en paraules del professor Quintana): «Filosofia de l'educació és l'explicació filosòfica de l'educació o l'elaboració crítica dels principis ideològics que pressuposen l'acte educatiu i que serveixen per a orientar- $10^{3}$.

La filosofia de l'educació ha d'estudiar dos aspectes fonamentals de la paideia:

1. L'estructura formal del procés educatiu (què és educar?). Tota pregunta - ja ho mostra molt bé Heidegger - implica una determinada resposta. Tota teoria pedagògica (implícitament o no) s'hauria

* Aquest article és un resum del tercer capitol de la meva tesi de llicenciatura llegida a la Universitat Autonoma de Bar* celona el dia 18 d'octubre de 1984 amb el títol: Vers una pedagogia de la mort. El problema de la finitud en el pensament de $M$. Heidegger i les seves implicacions en l'àrea de la filosofia de l'educació, dirigida pel professor doctor Octavi Fullat.

I aDic Eule der Minerva beginnt erst mit der einbrechenden Dämmerung ihren Flug.»

2 Segons J. M. Quintana, "Concepto de filosofía de la coucación", Enrahonar, núm. 5/6, p. 110; "La Pedagogia no és altra cosa que la Filosofia posada en pràctica».

${ }^{3}$ J. M. QUINIANA, op. cit., p. 116. necessàriament de preguntar què és educar. Segons la resposta que hom doni es podran elaborar els continguts o objectius materials del procés educatiu. Tanmateix hi ha respostes que fan impossible una determinada estructura material de la paideia (com ja veurem).

2. L'estructura material del procés educatiu (per a què educar?). Tota teoria pedagògica inclou necessàriament uns objectius, sense els quals seria absurd parlar d'educación .

\section{L'ESTRUCTURA FORMAL DEL PROCÉS EDUCATIU}

L'educació és un procés. No és estàtic sinó dinàmic. L'estructura fonamental del procés educatiu és tripartita. Es constitueix en forma triangular: l'educand, l'educador, i el contingut educatiu. Hom pot representar-la en l'esquema següent:

\section{CONTINGUT EDUCATIU}

(element en funció del qual es modifica la conducta)

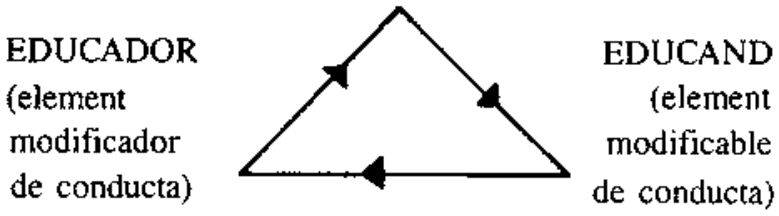

Aquest procés triangular-dinàmic no és, però, pacífic. Ans al contrari, és - com diu Octavi Fullatrivalitat, controvèrsia, pugna, lluita, violaciós.

L'educació és un enfrontament entre l'educador i l'educand. Aquesta és la més simple composició del procés educatiu. Una altra cosa ben diferent és la forma que ha de tenir el contingut educatiu. Hom ha de donar resposta a la pregunta què és educar, abans de respondre a per a què educar. Els coneixements, les finalitats, els pressupòsits, les ideologies, etc., han d'ésser envoltades segons una determinada forma. El que ara ens interessa no és què ha de saber l'educand, quins trets ha de tenir la seva formació, què li ha d'ensenyar l'educador,

4 Com diu molt correctament T. W. MOORE, Introducción a la teoria de la educación, Alianza Univ., p. 117: «Si no hi hagués coneixements a assolir $i$ alguns que mereixés la pena assolir-los, el concepte d'educació, tal com nosaltres l'entenem, no tindria sentit".

5 O. FULLAT, «El educar como absolución imposible o el fracaso teleológicon, Bordón, núm. 251, Sociedad Española de Pedagogia, gener-febrer 1984, p. 48. 
etc., sinó sota quina estructura formal oferim els continguts educatius, les finalitats pedagògiques. Té raó Moore en afirmar que «si hem de postular algun objectiu referent a la nostra tasca d'anàlisi, serà precisament formal, és a dir, que un objectiu de l'educació és formar un cert tipus de persona, un "home educat" " 6 . Es tracta, doncs, de mostrar la forma, el com assolir els continguts, les finatitats educatives de l'Anthropos, més que els continguts mateixos.

Veiem, en primer lloc, dos exemples representatius de teòrics de l'educació que no han diferenciat entre l'estructura formal i la material del procés educatiu: Durkheim i Neill. Ambdós podrien qualificar-se de reduccionistes en els seus plantejaments. El primer redueix la forma educativa als continguts sociològics; el segon als teleològics.

Analitzem a continuació aquesta problemàtica amb més detall.

1. La tesi originària de Durkheim és molt encertada i correcta: «L'home no és home més que perquè viu en societat ${ }^{7}$. Per a Durkheim, però, l'objectiu de l'educador rau a superposar a l'ésser individual que som nosaltres en néixer, un altre completament diferent i nou: l'ésser social.

Trobem, per altra banda, una prioritat de la societat per sobre l'individu. La tasca primordial de l'educació _-per a Durkheim- rau a crear "éssers socials»". Si ho analitzem en rigor, veurem que el concepte d'educació del pedagog francès no deixa d'ésser formal, malgrat que és un formalisme impur. L'anomenem així perquè implica un determinat contingut. Durkheim no diu de fet què és educar, sinó per a què hem d'educar, malgrat que aquest per a què és formal.

Si jo dic: "Educar és fer éssers socials", ta pregunta més coherent del meu interlocutor serà: «¿En quina societat?" La societat, la cultura, la civilització sempre és plural, $\mathrm{i}$-més obvi- les pautes de comportament són absolutament diferents d'una i d'una altra cultura. Per això, malgrat que el concepte d'educació de Durkheim no deixa d'ésser formal, sí que a priori implica determinar uns continguts per part del pedagog que l'adopta.

2. El cas de A. S. Neill, malgrat que en cert sentit

6 ๆ. W. MOORE, op. cit., p. 112.

7 E. DURKhelm, Educación y sociología, Península, p. 57. Cf. també, J.L. CASTILLEJO, «El marco socio-cultural de la educación", Teoria de la educación, p. 38.

8 E. DURKHEIM, op. cit., pp. 69 i 104. és paral-lel a Durkheim, té també unes profundes diferències amb aquest. Neill identifica el què és educar? amb el per a què educar?, però -a diferència de Durkheim- no és formal sinó plenament material.

En primer lloc, Neill dedueix erròniament (fal là̀cia naturalista) de la finalitat de la vida l'objectiu de l'educació. I és erroni perquè ho formula categòricament ${ }^{9}$. Neill es mou en una ètica propera a l'utilitarisme. És bo allò que és útil per a assolir la felicitat. La bona educació serà aquella que serveixi per a fer nens feliços, homes joiosos.

Una pedagogia existencial, una pedagogia de la mort, una pedagogia de la finitud, no pot fonamentar-se, com succeeix en el cas de Durkheim també, en les tesis neillinianes. La teoria de l'educa* ció de Neill, a més a més d'ésser incorrecta (car incorre en la fal-làcia naturalista), no serveix per a construir una pedagogia de la finitud perquè identifica l'estructura formal del procés educatiu amb la material.

3. L'home no posseeix la veritat. L'Anthropos existeix vers la veritat ${ }^{10}$. Però, com assolir-la? Com podem arribar a la veritat? La veritat és oculta, s'amaga. Cal, en conseqüència, desvelar-la. Aquest és el sentit autèntic del mot grec aletheia: "Quan traduïm aletheia per «desocultament" n-escriu Heidegger- en lloc de «veritat», aquesta traducció no és tan sols més literal, sinó que conté la indicació de transformar i de portar de nou amb el pensament el concepte habitual de veritat, en el sentit de conformitat de l'enunciat, en i vers aquell concepte encara incomprensible de desvelar i el „desvelament de l'ens»". A partir d'aquí hom pot formular una nova estructura formal del procés educatiu que sigui adient a una pedagogia de la mort.

Aquest anhel de veritat apareix ja en l'antiguitat grega amb Sòcrates $i$ es dogmatitza amb Plató $i$ Aristòtil. Aproximarem així molt més radicalment la paideia i la filosofia. Veiem-ho tot seguit.

Per a Plató, el filòsof era el que assolia la veritat:

-Aleshores a qui dius tu veritable filòsof?

-Tan sols aquells als qui agrada de contemplar la veritat ${ }^{12}$.

9 A.S. NEILL, Summerhill, F.C.E., pp. 102 i 36.

$10 \mathrm{~K}$. JASPERS, La fe filosófica ante la revelación, Gredos, p. 498.

"M. HeJDEgGer, Vom Wesen der Whrheit, a Wegmarken, V. Klostermann, p. 188.

12 Plató, La República, a Obras Completas, Aguilar, p. 757 . 
Plató pensava que el filosof posseïa la veritat $i$ que, en conseqüència, havia de convertir-se en el cap de la república. Aquí és on comença la seva teoria política i educativa. La veritat és única, Ia veritat és l'ésser. El filòsof -i en aquest sentit ens trobem molt més a prop de Sòcrates que de Platóés el que anhela la veritat i la descobreix, la desoculta, la desvela. La veritat és cercar l'ésser. El filòsof és l'encarregat de buscar l'ésser, de presentar-lo, de desvelar-lo, d'exposar-lo. La tasca de l'Anthropos rau a trobar el seu ésser autèn. tic, a descobrir-se a si mateix com a constituït des d'unes estructures ontològico-fonamentals (o transcendentals).

És a partir d'aquesta concepció de la filosofia com a recerca de la veritat i d'aquesta com a des. velament d'allò arcaic, que podem postular l'estruc tura formal del procés educatiu. Educar serà un acte de coneixement, un desocultament de la realitat existencial de l'home ${ }^{13}$. Educar és formalment una invitació a l'aletheia, un «desemmascarar», perquè l'educand pugui existir -si així vol fer-ho-autènticament, segons i a partir de la seva real i veritable estructura ontològico-existencial.

Mercès a aquesta concepció de la paideia assolim l'estructura material del procés educatiu: el Thanatos. "Educar - diu Octavi Fullat- consisteix a donar a conèixer l'home, cada home. No tots som pintors, físics o polítics; tots, en canvi, som mortals. La mort no la podem delegar. Aquí radica la nostra fonamental singularitat. No podem deixar-ho de tenir present en educació» ${ }^{14}$. El que ens aporta de nou aquesta concepció de la paideia és el fet que el filòsof pot descobrir les estructures ontològico-existencials des de les quals edificar hipotèticament una teleologia educativa.

4. L'educació entesa com a desvelament d'un ésser ocult a conèixer és l'estructura formal del procés educatiu que ens interessa per poder edificar una pedagogia de la mort. Ara bé, cal anar però amb molta cura si no volem fer de l'aletheia un justificant de l'educació bancària en lloc de la problematitzadora.

Si l'educador posseeix la veritat absoluta, eterna, immutable, l'educació esdevé una educació ternària, que no és reversible, és a dir, que passem del triangle:

13 P. FRFIRE, Pedagogía y acción liberadora, Zero, p. 79. 14 O. Fullar, Las finalidades educativas en tiempo de crisis, Hogar del Libro, p. 231.

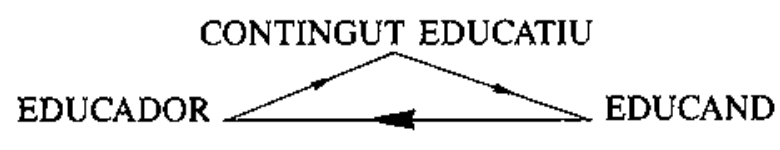

a un altre:

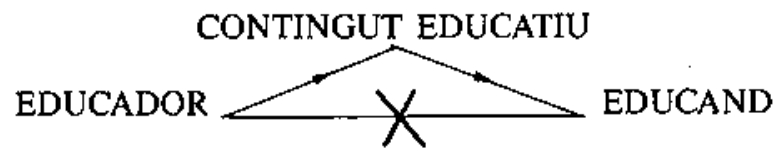

L'educació s'entendria aleshores com una «mena de transacció entre un recipient ple i un altre buit. El mestre és un home ple, un dipòsit de coneixements, habilitats i actituds socialment importants, mentre que l'alumne és buit i necessita que se l'ompli»' ${ }^{15}$. Aquest tipus d'educació -anomenada per Freire «bancària»- es contrària a la veritat i no serveix per a establir una pedagogia de la mort. Mitifica el món, pretén que hi ha una ve ritat que és natural i que tan sols posseeix l'educador (o el polític), però que, paradoxalment, no és constatable amb la realitat. Si la veritat filosòfica -encara que el mètode utilitzat sigui absolutament rigorós- esdevé incontrastable i -alhora- única i necessària, ens trobem davant una ideologia, en el sentit més pejoratiu del mot ${ }^{16}$. L'educand no té un paper actiu, sinó passiu, merament passiu. L'educand rep i no dóna. L'educand memoritza, repeteix, arxiva, col-lecciona ${ }^{17}$.

L'educació «bancària» esdevé conservadora de la realitat, dogmàtica, dictatorial. Enfront d'aquesta caldria oferir una educació "problematitzadora", crítica, creadora, singular, existencial, si volem construir una pedagogia de la mort ${ }^{18}$.

L'educació com a desvelament, si vol posseir alhora una forma crítica i fonamentada en la llibertat, no pot basar-se en la dominació ni en la domesticació. L'educació «bancària» és l'educació per a la manca i l'absència de l'esperit crític, mentre que l'educació «problematitzadora» és l'educació per a la llibertat ${ }^{19}$. Hem d'entendre el mot liber-

15 T. W. MOORE, op. cit., p. 35

16 P. FreIRE, Pedagogia del oprimido, Siglo XXI, p. 95.

17 lbid., p. 76.

$18 \mathrm{~J}$. BOWEN, Historia de la educación occidental (I), Herder, p. 16: «En l'àmbit educatiu es plantegen actualmenı moltes qüestions que dificulten el pensament $i$ obstaculitzen l'acció; entre totes elles ocupa un lloc preferent el conflicte entre una concepció de l'educacio com activitat de conservació per un costat i com una activitat de creació per un altre".

19 P. FREXRE, La educación como práctica de la liberad, Siglo XXI, p. 26. 
tat en el sentit amb què l'empra Heidegger. Per al filòsof de Freiburg, Freiheit té el sentit del descobriment de la veritat. Només des del desvelament, des de l'aletheia que l'educand realitza (autorealitza), pot assolir les seves estructures ontològiques i ek-sistir.

Si l'educació s'entén com invitació a l'aletheia, i aquella no és «bancària" sinó "problematitzadora”, la tasca de l'educador consistirà a oferir a l'educand els mitjans perquè aquest pugui passar d'un coneixement a nivell de la doxa a un coneixement a nivell del logos. Així, l'educació «problematitzadora" esdevé educació per al diàleg, per a la individualitat, per a l'autonomia, per a la singularitat.

El descobriment del logos de l'estructura existencial de l'Anthropos possibilita l'educand perquè aquest realitzi un comportament determinat: l'home s'ha de com-portar obert a l'ésser, és a dir, $e k$ sistir autènticament ${ }^{20}$.

Com a resum de l'exposat al llarg del present capítol oferim l'esquema següent:

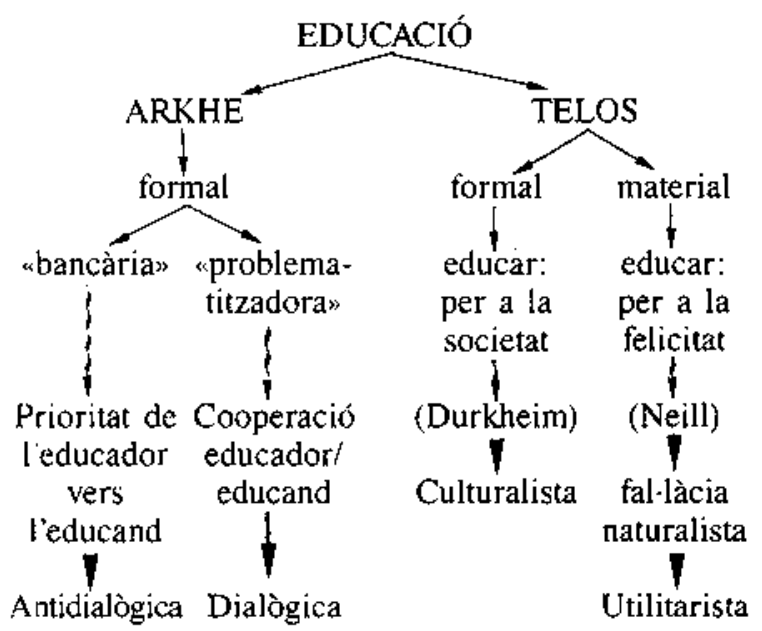

\section{L'ESTRUCTURA MATERIAL DEL PROCÉS EDUCATIU}

Una pedagogia de la mort ha de fonamentar-se en la concepció de l'educació com a invitació a l'aletheia, a la veritat. Per això mateix el que cal és des-velar les nostres estructures ontològicofonamentals (en els seus dos vessants: transcendentals i existencials o vitals), entre les quals $\mathrm{fi}^{-}$ gura -és indubtable - la finitud (transcendental)

20 M. HetDegger, Vom Wesen der Wahrheit, p. 184. i la traducció d'aquesta en l'àmbit existencial: la mort.

Lactualitat de la vivència de la mort en la cultura occidental contemporània és absolutament con* trària a l'autoconsciència de la finitud. Volem que els malalts vagin a morir a l'hospital en lloc de ferho a casa; s'amaga al moribund la imminència de la seva mort; massa sovint àdhuc els familiars no n'estan assabentats; l'eutanàsia està penalitzada i/o prohibida, i queda en mans del metge la decisió definitiva, que pot allargar la vida "artificialment» tant com vulgui, etc. En resum: la mort ha deixat d'ésser allò més personal, allò més irrepetible $\mathrm{i}$ irrenunciable, per passar a ésser allò que tinc de més estrany, allò que és més aliè a la meva constitució.

L'aletheia ens mostra que l'Anthropos està constituït ontològicament com a moriturus ${ }^{21}$. La tasca de la filosofia de l'educació -entesa ara també com a teleologia educativa - que vol fonamentar una pedagogia existencial és la de plantejar-se l'interrogant següent: si l'ésser de l'existència humana és ontològicament finit, hem d'educar per a la mort i des de la finitud? Si volem fer una educació en conformitat amb l'home és obvi que sí. En conseqüència, educar des de la finitud, des de l'(auto)consciència de la finitud, és educar autènticament, en el sentit heideggerià del mot, és a dir, educar conforme a l'ésser, a la veritat, car la veritat és l'ésser i l'ésser de l'Anthropos és finit.

Educar per a la mort suposa educar per a la $\sin$ gularitat, per al present, per a la llibertat (entenem també aquí el significat de Heidegger). «El Jo - escriu Octavi Fullat - no tan sols assoleix cos davant el tu -el del pare o del mestre-, se sent viu i real quan s'enfronta amb la mort. El finament, quan encara no ha arribat, és el notari que dóna fe de la vida del meu "Jo". Per què priven als fills, i educands en general, del coneixement de la mort quan aquest promet tanta riquesa interior a més de constituir una dada?» ${ }^{22}$. La mort hauria d'ésser el centre de l'estructura material del procés educatiu, és a dir, la finalitat educativa fonamental. Una pedagogia existencial, fonamentada en les estructures ontològiques de l'ésser humà, no pot pas

${ }^{21}$ Heidegger a la seva obra Sein und Zeit mostra que la realitat humana està constitü̈da ontològicament com a Sein zum Tode. Aquest existenciari juntament amb la Sorge i la Zeitlichkeit formen el "cercle hermenèutic fonamental". (Cf. $\$ \S$ 39-44, 46-53; 65 i ss. de Sein und Zeit.)

22 O. FULLAT, Las finalidades educativas en tiempo de crisis, p. 243. 
oblidar-ho. Només educant per a la mort eduquem per a la creació d'éssers singulars, únics i irrepetibles, de persones. (Cal recordar la tesi de Heidegger: «Ningú no pot prendre a un altre el seu morir».) Però a més a més, l'educació per a la mort suposa l'educació per a l'agonia. Tot Anthropos que es descobreix com a Sein zum Tode, com a moriturus, no podrà quedar-se mai indiferent.

La darrera pregunta de l'home és per què he de morir. La qüestió es fa més greu quan l'educació es mou en un àmbit teista, quan en l'horitzó pedagògic apareix la Transcendència. Tampoc aleshores no hi ha resposta del perquè de la meva finitud. Per això, la lluita esdevé la conseqüència més radical de la teleologia educativa que defensem. L'Anthropos és un ésser agònic que convertirà la seva existència en un constant preguntar-se per les causes darreres de la seva vida. L'educació des de la finitud i per a la mort es converteix en una educació per a l'agonia. En definitiva, la pregunta «per què he de morir" es pot traduir en una altra que ja es qüestionava Heidegger a la fi de Was ist Metaphysik: "per què hi ha ésser en lloc de no-res?".

\section{L'HORITZÓ DE L'ESPERANÇA}

El problema de la pedagogia de la mort ha estat desenvolupat fins ara com el d'una educació que $a c a b a$ amb la mort. Però la finitud és inseparable de l'esperança. El problema del límit tempta el filòsof pel més enllà del límit. Fins ara hem assolit una dada fenomenològica fonamental: l'Anthropos és l'únic -de tots els éssers vivents- que sap de la seva finitud ${ }^{23}$. Des de la filosofia de Heidegger, des de la seva concepció de la realitat humana com a Dasein, el «després de la mort» escapa de les possibilitats de l'home en tant que ésser-en-el-món. L'home -pensava el filòsof de Freiburg - és un constant «encara no» (Noch nicht), un mancament, una carència. Per a Jaspers, tanmateix, aquest «encara no» implica que la realitat humana és capaç de sobrepassar la seva facticitat. L'home - escriu el pensador de Basel- «és l'ésser que en la seva història està vinculat a l'eternitat" ${ }^{24}$.

Si a més a més d'incloure la mort com a finali-

23 K. JASPERS, "Der philosophische Glauble», Vemunft und Freiheit, p. 155.

${ }^{24} \mathrm{~K}$. JASPERS, La fe filosófica ante la revelación, Gredos, p. 478 . tat educativa hi afegim l'educació per a l'esperança en la Transcendència... no podríem així assolir part d'un impossible? L'educand desvelaria l'ésser de la seva autèntica realitat $i$-ensems- sorgiria una llum en la fosca nit de l'angoixa. L'angoixa podria quedar aufgehoben en la Transcendència; però, tanmateix, hi afegim un grau molt superior d'agonia. Aquesta, doncs, augmenta quan obrim els ulls a l'Absolut. L'home existeix des de la finitud (aquesta és transcendental -en sentit kantià) i, en tant que ésser finit, descobreix la Transcendència. Educar per a la veritat ontològica és educar per a la mort i des de la finitud. Això ens duu a l'angoixa ontològica $i$ a l'agonia existencial. L'home també esdevé un animal agònic perquè té els ulls fixos en la Transcendència, perquè se sap moriturus, ontològicament finit $\mathrm{i}$ condemnat a la destrucció final. L'esperança, doncs, és l'única, la darrera possibilitat de salvar ensems la veritat de la mort i la superació (parcial) de l'angoixa. L'esperança no atempta contra la finitud, ans al contrari, la reafirma.

Mort..., vida..., dos contraris, dos enemics que conviuen dramàticament en l'existència de l'An. thropos. La recerca d'una pedagogia de la mort ens ha obert l'horitzó de l'esperança, de la Transcendència. Tal vegada sigui una llum feble, una claror enigmàtica o, àdhuc, un resplendor fals. Impossible saber-ho amb absoluta seguretat. Però, si més no, sí que la pedagogia de la mort desvela una pedagogia de l'esperança... perquè «és justament davant l'experiència tràgica de la mort, quan en el cor de l'home floreix més viva que mai l'esperança»" 25 .

\section{BIBLIOGRAFIA}

BOWEN, J., Historia de la educación occidental, (vol. I: «El mundo antiguo. Oriente próximo y el mediterráneo. 2000 a.C.-1504 d.C.", Herder, Barcelona 1976.

Castillejo, J. L., Escamez, J., MaríN, R., Teoría de la educación, Anaya 2, Madrid 1981.

COLOMER, E., Heidegger; pensament i poesia en labsència de Déu, Estela, Barcelona 1964.

DURKHEIM, E., Educación y sociología, Península, Barcelona 1975.

25 E. COLOMER, Heidegger: pensament i poesia en labsència de Déu, Estela, p. 20. 
FREIRE, P., La educación como práctica de la libertad, Siglo XXI, Madrid 1983.

-, Pedagogía del oprimido, Siglo XXI, Madrid 1983.

-, Pedagogía y acción liberadora, Zero, Madrid 1978.

Fullar, O., Filosofias de la educación, CEAC. Barcelona $1979^{2}$.

-, «El educar como absolución imposible o el fracaso teleológico", Bordon, núm. 251, Sociedad Española de Pedagogía, enero-febrero 1984, pp. 45-50.

-, Las finalidades educativas en tiempo de crisis, Hogar del Libro, col. "Navidad", Barcelona 1982.

HEIDEGGER, M., Sein und Zeit, Max Niemeyer Verlag, Tübingen 1979.

-, Was ist Metaphysik?, a Wegmarken, V. Klostermann, Frankfurt am Main 1978.

-, Vom Wesen der Wahrheit, a Wegmarken, V. Klostermann, Frankfurt am Main 1978.
JASPERS, K., Philosophie, Springer-Verlag, Berlín, Göttingen, Heidelberg 1956 (especialment: Zweiter Band. Existenzerhellung Grenzsituationen: Tod).

-, Der philosophische Glaube, (a Vernunft und Freiheit), Europäischer Buchklub, Stuttgart-ZurichSalzburg.

-, La fe filosófica ante la revelación, Gredos, Madrid 1968.

MOORE, T. W., Introducción a la teoría de la educación, Alianza Editorial, Madrid 1983.

NEILL, A.S., Summerhill, F.C.E., Mèxic 1982.

PLATo, La República, a Obras Completas, Aguilar, Madrid 1979.

Quintana, J. M., "Concepto de filosofía de la educación», Enrahonar, núm. 5/6: «Filosofia de l'educación, Departament de Filosofia, Universitat Autònoma de Barcelona 1983, pp. 109-116. 